\title{
Integrated health and social care for older persons: Theoretical and conceptual issues
}
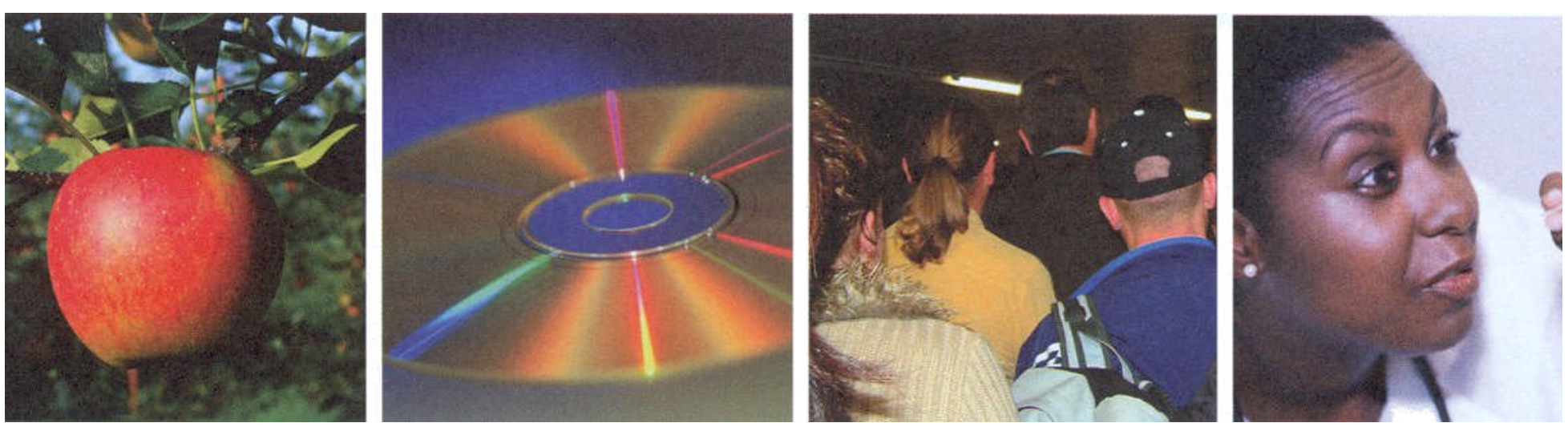

Andy Alaszewski, Jenny Billings,

Kirstie Coxon

Centre for Health Services Studies

University of Kent

July 2003 


\section{PROCARE}

Providing integrated health and social care for older persons issues, problems and solutions

European Centre for Social Welfare Policy and Research (co-ordinator) | Danish National Institute of Social Research (SF) | Research Society for Gerontology - Institute of Gerontology at the University of Dortmund | National Research and Development Centre for Welfare and Health (STAKES) I Union nationale interféderale des œuvres et organismes privés sanitaires et sociaux (Uniopss) | National Centre for Social Research - Institute of Social Policy (EKKE) | emme\&erre s.p.a.| Studio Come s.r.t. Dr. Hilda Verwey-Jonker Institute | University of Kent at Canterbury - School of Social Policy. Sociology and Social Research (SPSSR)

\section{Integrated health and social care for older persons: Theoretical and conceptual issues}

\author{
Andy Alaszewski \\ Jenny Billings \\ Kirstie Coxon
}

Centre for Health Services Studies

University of Kent at Canterbury

UK

\section{July 2003}

Co-financed by the

European Commission, DG XII

Fifth Framework Programme Quality of Life and Management of Living Resources Contract No. QLK6-CT-2002-00227 


\section{CONTENTS}

Introduction

p.3

1. IDENTIFYING THE NEED FOR AND THE IMPEDIMENTS TO INTEGRATED CARE

1.1 The importance of integrated care for older people p.3

1.2 Ageism and age discrimination

p.7

1.3 Organisational complexity

p.9

1.4 Summary and Comment: Impediments to integrated care

p.12

2. APPROACHES TO INTEGRATED HEALTH AND SOCIAL CARE

2.1 Structural integration

2.2 Joint working: Process-centred collaboration

p.15

2.3 Person-centred, seamless care

p.17

2.4 Summary and Comment: Approaches to integrated care

3. ASSESSING INTEGRATION: ORGANISATIONAL AND PERSONCENTRED OUTCOMES

3.1 Care pathways and need: the systems approach

3.2 Risk and integration

3.3 Collective or community perspectives: social inclusion

p.24

3.4 Summary and Comment: Assessing integration

4. CONCLUSION 


\section{Integrated health and social care for older persons: Theoretical and conceptual issues}

\section{INTRODUCTION}

This paper provides the theoretical and conceptual framework to the fieldwork component of the PROCARE programme. The first section explores the need for and impediments to providing integrated care for older people in Europe. The second section is a discussion of the alternative approaches and definitions of integrated care, which emphasises the importance of a personcentred approach. The third section examines the alternative ways in which the impediments to integrated care can be overcome. The last section considers ways in which integrated care can be evaluated.

\section{IDENTIFYING THE NEED FOR AND THE IMPEDIMENTS TO INTEGRATED CARE}

In this section we consider the factors that make integrated support of older people particularly important and then consider the particular impediments to the provision of integrated care that often result in services for older people being more fragmented than those for younger people with similar health and social difficulties.

\subsection{The importance of integrated care for older people}

While all users of health and social care should be able to access and experience seamless or integrated care, for older service users integration is especially important. Older service users tend to suffer from a combination of health problems, and may at the same time experience increasing isolation, declining social support and increased personal vulnerability.

Impact of ill health on older people

Ageing is associated with increasingly complex and often inter-related problems encompassing physical, psychological and social health. Older people tend to experience higher rates of chronic illness such as diabetes, heart disease or disability associated with strokes. When older people experience an acute episode of illness resulting from, for example flu or a fracture following a fall, not only is treatment more complex and based on a wider range of expertise and skills but recovery and recuperation and is often slower and longer. Grimley Evans (2001, p. 408) has identified the following characteristics of illness in later life:

- Rapid deterioration if untreated

- High frequency of multiple disease

- Cryptic or non-specific presentation

- High incidence of secondary complications

- Frequent need for active rehabilitation

- Frequent need for help in resettling in the community 
The complexity of treating older people is reflected in their length of hospital stay. In most European countries the development of a more active approach to treatment, especially surgery, has meant the average length of hospital stay has been progressively cut. For example, across PROCARE participating countries, the mean length of acute care stay in days has dropped from 10.3 in 1980 to 6.7 in 1999 (OECD data 2002).

However, the reduction of the length of stay of older people has fallen more slowly than that for younger people with the result that in all European countries older people stay on average three times as long in hospital. For Example, in the UK the mean acute care length of stay was 6.2 days in 2000 (OECD 2002), but the average length of stay for a person admitted to the specialty of geriatric medicine was 23.4 days (compared with 8.2 days for 'general medicine', that is, medical admissions of patients younger than 60). Perhaps not surprisingly, patients admitted for 'rehabilitation' had longer mean stays of 49 days (Department of Health (DoH) 2002a), and this is likely to reflect the fact that, at least in the UK, length of stay for the older person is related in part to the problems of arranging a safe discharge back to the person's own home.

This trend is also evident in surgery. Generally the majority of people being admitted for surgery are younger. UK admission figures for 2001-2002 show that only 18\% of surgical patients are aged 75 or above, and only $14 \%$ of cardio-thoracic surgery patients are over 75 (DoH 2002a). Whilst this is in some ways unsurprising given that combinations of heart and respiratory problems, arthritis, diabetes, cognitive difficulties and sensory impairments may mean that surgical and anaesthetic procedures are particularly difficult for older people, there remains evidence that surgery which benefits younger persons attracts numerous performance targets, whilst waiting lists for operations such as hip replacements and cataract surgery remain long. For example, according to central government statistics, which may themselves mask wide variations between regions, the mean waiting time for general surgery in England is 63 days, for orthopaedic surgery 170 days and for ophthalmology 144 days (DoH 2002a).

The complexity of providing health care for older people requires collaboration between and integration of a range of different health and social care professionals. This can be seen in relation to medication. Many older people are routinely prescribed a range of medication to manage their chronic health problems. These medications are usually prescribed and reviewed by their community physician and where necessary a community nurse will help the older person manage their medication. If an older person is admitted to hospital and professionals do not collaborate then there can be considerable problems with medication:

- New medication may be prescribed which interacts negatively with existing medication;

- Routine medication may be cut or changed without due regard to ongoing health problems;

- Ward nurses may take over the administration of all medication deskilling the older person.

These difficulties may be exacerbated if on discharge professionals do not collaborate and community health and social care workers are unaware of or choose to disregard the decisions made in hospital (DoH 2001b).

When older people are acutely ill, it is often in the context of enduring long-term illness. As a result not only is their treatment complex, lengthy and expensive, it also requires the coordination of a range of skills and expertise contributed by different agencies. If these skills are not effectively integrated, there is at best inefficiency with one agency duplicating or undoing the work of another and at worst there may be serious harm for the older person because treatments interact negatively or because they fall through the welfare net. 


\section{Challenges of maintaining older people's health}

While the health of older people has undoubtedly improved with people managing to remain healthier for longer, it is still the case that ageing is associated with increased risk of physical and mental disability. Such disability increases the vulnerability of older people to harm. While some risks are well recognised and documented, for example the increased risk that older people have of falling (Cryer and Patel 2001), other risks have been recognised more recently. In the UK there is a growing awareness of and literature on elder abuse and the risks of financial exploitation, emotional harm and violence from carers and others (Stanley, Manthorpe and Penhale 1999). Protecting older people from harm requires effective collaboration between emergency services such as police, fire and ambulance as well as from the more routine services.

There is also a subjective dimension to vulnerability. Mental well-being can be linked to a personal sense of security (Wilkinson 2001). In modern society it is possible to identify the phenomenon of anxious or timid prosperity in which increased levels of collective safety and welfare are paradoxically associated with increased levels of anxiety about personal security (Taylor-Gooby 2000). Increases in objective levels of 'safety' do not necessarily lead to increases in perceptions of individual well-being, as demonstrated, for example, in studies of fear of crime, which consistently show that the least 'at-risk' group, namely elderly females, are the most fearful (Jefferson and Holloway, 1997). The literature also indicates a relationship between physical disability and low self-esteem (Taleporos and McCabe 2002) and a reduced perception of self-efficacy (Schieman and Campbell 2001), which are also likely to contribute to psychological vulnerability and perception of risk. Thus if health and welfare agencies are to maximise the well-being of older people they not only need to objectively enhance safety, they need to develop means of empowering older and functionally disabled people that challenge such perceptions of risk or vulnerability.

These issues indicate a number of existing challenges to the ideal of a holistic and proactive (or preventative) approach towards helping older people stay healthy and socially integrated. In some European countries, there is evidence of policies that aspire to ever wider crossdepartmental collaboration. For example, recent policy documents from the Dutch government demonstrate the growing interest in housing and welfare issues, and recognise that these issues have been neglected (Ex et al 2003). This approach is based on the premise that the needs of older people go beyond the basic provision of care. Frail elderly people also want suitable housing, and to be able to participate in society, social contacts and recreation. There is evidence that the 'person centred' approach to care which this requires is being addressed by organisations in the Netherlands. For example, a policy document of 'Arcares' (the Dutch professional association of homes for the elderly) shows a person-centred approach, stating that the service providers should look at care problems within the broader perspective of the client's well-being, and that clients' unique life styles and preferences should be identified and taken into account (Acares 2002). Because the older person's need for care and services is integral in nature, it follows that supply should include an integral package of care, welfare and housing-services. This integral approach has led to the insight that communication between separate departments who are supplying care could lead to an overall reduction in demand. For instance, participation in activities may prevent loneliness and depression, and consequently may reduce the demand for social care.

One consequence of providing specialist accommodation (such as sheltered or warden housing) is that older people may move away from their immediate family or neighbourhood, and therefore may be both living alone and socially isolated. Even where this is a result of personal choice, there is a danger that such individuals will fall through the welfare net if there is weak 
integration between different parts of the health and social care systems. Although some European countries appear to have successfully addressed this problem, the 'Procare' National Reports (see http://www.euro.centre.org/ec 6.htm) suggested that integration frequently breaks down at the point of discharge from hospital.

\section{Cultural diversity in Europe - The role of families and 'informal care'}

The risks to older people with long-term care needs are being exacerbated by the decline of social support in industrial societies. Social trends in such societies are now well established and recognised. At the same time as the population is ageing through increased longevity, the 'informal' support from families is reduced by increased economic migration together with the trend for women to remain longer in paid employment (Kavanos and McKee 1998). Furthermore, changing social norms and expectations mean that even where such family is available they are less likely to accept an obligation to provide care and support. In some Northern European countries such as Denmark, family care is not even factored into care provision (Colmorten et al 2003), the consensus being that the state will provide support to older people. In the UK, services 'top up' the level of family care available, although family support is not a legal obligation. In fact, 'informal' or family carers provide the majority of long-term social care in the UK (Twigg and Atkin 1994). By contrast, in Germany there is both a legal obligation and social expectation that families will provide and finance continuing health and social care (Roth and Reichert 2002). However even in this system actual enforcement of such obligations is limited and there is evidence of shifting social norms and expectations.

\section{Ageing and gender}

A wealth of research has been carried out on both older people and on the social situation of women. However, research on ageing from a gender perspective is still scarce, despite the fact that women are over represented in the ageing population. In many cases, differences in the standard life courses of men and women become more pronounced in later life. Also, women are more affected by care than men in two ways: as those cared for and as those who care. Specifically, $18 \%$ of the population (that is, almost every fifth person in Europe) are women aged 50 or more (European Commission 2002/2004). Yet women and men do not receive the same (or similar) care, even for the same conditions. American studies show women are less likely to receive high-tech services, and tend to receive less aggressive care for conditions such as heart disease and cancer (McKinlay 1996). Men are taken more seriously than women in health care, and women's health problems may be attributed to psychological or emotional factors rather than to physiological disease processes (Macintyre et al 1999).

In terms of women's higher life expectancy and the ageing of the population as a major trend in European countries, women are a specific target group of integrated health and social care. They are often the carers of the person in need of care -as professionals or as immediate family - but may also be in receipt of care. Older women are very often dependent on community or institutional care. While older women often care for their husbands or other male relatives until their death, due to their own longer life expectancy, they may not be able to rely on this kind of help. One main difference in the life situation of older men and women is that women can be seen as the "covert resources of the social policy" with respect to their roles as informal carers (family care and volunteers). Also, the social and financial situation of older women is usually more tenuous than that of older men. Older women have less income and fewer benefits than men, and in general have worse living conditions then men their age do (Bundesarbeitsgemeinschaft der Senioren-Organisationen et al 2001).

Thus, it should be kept in mind that most people working in integrated care close to the users are women, that most service users - meaning those in need of help and care as well as informal 
carers - are also women, whereas those in the higher management positions of integrated health and care services (or making policy decisions) are likely to be men. It is therefore important to consider which aspects of the 'Procare' study findings reflect gender issues, and which can be generalized between women and men.

\section{Comment}

In modern society, health and social care agencies have to deal with a major paradox. Major social changes such as the decline of infectious disease and improvements in nutrition have enabled an increasing number of people to live longer. Other social changes such as reduced family size, increased personal mobility and rising divorce rates mean that the level of social support for older people is falling. In these circumstances, improved integration is not an option - it is an imperative. One advantage of the advances in home care and rehabilitation which have taken place is that there is greater understanding of how to care for people at home in a costefficient way, and an argument for integration is that it both epitomizes best practice and correlates well with the expressed preferences of both users and carers.

\subsection{Ageism and Age Discrimination}

'Ageism' refers to cultural and social processes that discriminate against older people because they are old (Tinker 1996), excluding them from the mainstream of society and depriving them of their full rights as citizens. This discrimination is based on the stereotyping of older people as intrinsically incompetent and dependent and less likely to benefit from treatment (Bytheway 1995).

Ageism may be evident in the decisions individual professionals make about treatment as well as in institutional decision making especially in terms of access to services and allocation of resources. Both forms of ageism act as impediments to integrated care:

'Ageism is a process of systematic stereotyping of people on the basis of age. Wade suggests that such stereotyping allows younger people to see older people as different; 'thus they subtly cease to identify with their elders as human beings' (Brooker et al, 1997, p. 8).

\section{Professional decision-making and ageism}

In publicly funded services, clinicians should ground their decisions in clinically relevant data. However analysis of clinical decision-making indicates that non-clinical factors, such as age, gender and ethnicity influence clinical decisions. For example in the treatment of heart disease in the UK older women are less likely than other groups to receive active treatment (Dudley et al 2002, Bowling et al 2001):

'Older people, and older women in particular, are less likely to receive appropriate cardiological investigation-from echo-cardiography to measuring cholesterol concentrations. Older people are more likely to have more severe disease and to be treated medically rather than surgically' (Bowling et al 2001, p. 286).

The net effect of such ageism is that many older people with heart disease do not experience an integrated service. They will tend to experience clinical delays and inappropriate referrals, i.e. to specialists in geriatric medicine rather than cardiologists. This increases the likelihood that they will enter the hospital system for emergency treatment of a heart attack or stroke rather than for 
routine investigation and preventative therapy. This leads to more complex treatment and rehabilitation, and a consequent increase in the need for sophisticated service co-ordination.

\section{Institutional ageism}

This term relates to a potentially ageist agenda which may exist within the collective decision making of health and social care agencies. As Bowling et al (2001, p.286) note, institutional ageism is rarely explicit. It is not politic to admit that older people are being deprived of access to services because of their age, and it is often concealed within arguments about clinical effectiveness or value for money, i.e. that older people will not benefit from certain services or procedures. In the UK, the Government's 'National Service Framework for Older People' has identified the existence of age discrimination in the provision of health and social care:

'Some evidence suggests there has been age discrimination in certain areas of health care. In 1991, 20\% of cardiac units operated upper age limits and $40 \%$ had an age-related policy for thrombolysis... Many older people and their carers have also found that palliative services have not been available to them...For social care, there is some evidence that councils can discriminate against older people where they apply commissioning strategies that are not sufficiently flexible to take account of individual needs... There is also considerable variation across the country in the range of services available to older people and their families or carers. Older people from black and minority ethnic groups can be particularly disadvantaged and are likely to suffer more discrimination in accessing services' (DoH 200la, pp. 16-17).

Institutional ageism can affect integration directly and indirectly. Health and welfare agencies often provide services to a range of users. If low priority is given to older users then less time and resources within the agency may be given to ensuring that services for older people are effectively integrated both within the agency and with other agencies. For example in social services department in England high priority is given to child protection and to the lead role that social services departments play in co-ordinating overall child protection services. There are serious consequences for senior managers if they fail to protect a child. Yet failure to protect an older person appears to go unnoticed, or may be attributed to their age and condition rather being considered a weakness or shortcoming of the care system. Also, there is less pressure to coordinate services for older people. While there is pressure on social services to speed up assessment to reduce hospital bed blocking, individual failures tend not to attract media and ministerial concern, so there is less interest in and incentive for collaboration.

\section{Comment}

It is generally acknowledged that both individual practitioners and health and welfare agencies discriminate against older people. Such ageism is extremely difficult to combat as it is based on perceptions that have been internalised. Individuals and agencies are likely to be unaware and even deny that they are discriminating.

Ageism creates a major impediment to effective integration of services. If older people are denied early access to health and social care then they are more likely to access services in an emergency, which reduces the time and scope for integration. Agencies themselves may recognise the benefits of effective collaboration but given limited time and resource may concentrate on collaboration for other service users who are perceived to be more vulnerable, e.g. children, or more dangerous, e.g. individuals with mental health problems. 


\subsection{Organisational complexity}

The main impediment to the provision of integrated care for older people comes from the fragmentation and lack of coherence of the health and social care system. The structure of health and social care systems in Europe tends to be divided horizontally between levels of government and vertically between agencies with different functions. Such structural divisions tend to reinforce conflicts between professions and with boundary and demarcation disputes in which professions often use their control of information and knowledge to maintain or increase autonomy and control. These tensions are heightened by competition between professions and agencies over the allocation of scare resources.

\section{Structural complexity}

While the social care system should be a unified entity which responds in a coherent and integrated fashion to users, in reality it is highly fragmented and competitive with different parts ready to blame each other when things go wrong.

In most of the PROCARE countries it is possible to identify a vertical division of functions. Central government is normally responsible for policy making, setting the framework of resource allocation and establishing the legal framework of the health and social care system. The actual delivery of services is delegated to the sub-national level. At this level there tends to be a further split between regional/county level and municipal/district level. This split is particularly important for health and social care because the responsibility for the provision health care often resides with the larger regional/county government while the smaller municipal/district government takes responsibility for the provision of social care. For example, in Denmark, the regions (counties), of which there are 16, are responsible for healthcare. Social care is the responsibility of the 275 municipalities, and this leads to widespread variations in service provision (Colmorten et al 2003). Similarly, in Austria, health care is regulated mainly by federal government, whereas social care is the responsibility of the nine provincial governments (GrilzWolf et al 2003). A recurring feature of the UK system has been attempts to create geographical co-terminosity for health and social care agencies (Alaszewski et al 2003), so that health and social care are provided for the same distinct population albeit by different organizations, as this seems likely to reduce barriers to integrated working, however this has not been achieved successfully to date.

Horizontal functional division reinforces these vertical divisions. At central government level responsibility for the range of policies affecting older people is frequently divided between and within ministries. At local levels similar divisions exist between agencies responsible for the delivery of health and social care. A common finding at least in the Northern European countries featured in the 'Procare' study is that whilst local authorities are responsible for personal care, housing and transport provision, these services are each provided by organisationally distinct sections of the responsible authority and that planning and strategic approaches tend to happen individually and in isolation of other departments (e.g., UK, Finland, Netherlands). These organisational divisions tend to impede the provision of integrated care, as the following excerpt from the 'Finland' Procare national report illustrates:

'A large scale development between social and health sectors was begun in the year 1991, when the Ministry set up a working group to make a proposal for an action programme to help improve the service structure. The programme recommended, for instance, the improvement of co-operation between social and health care services by uniting the municipal health and social service committees 
and respective agendas (Seiskari 1997: 149). However, until 2000 only $38 \%$ of Finland's municipalities $(\mathrm{N}=448)$ had followed this recommendation and even in that case health care and social welfare services continue to be separately arranged on the practical level' (Salonen and Haverinen 2003, p.4).

Such structural fragmentation of services creates integration problems that are now well documented and are a product of contradictions within contemporary systems of government. Policy contradictions may also be described as resulting from the diversity within national systems, for example differences between sources of funding for health and social care between countries, and the diversity that may result from a mixed market of private, public, lay and voluntary care providers.

While governments are committed to integrated services they are also preoccupied with the problems of funding the welfare system and therefore of obtaining maximum value for money from the public funds allocated. To achieve best value, governments are developing performance assessment structures based on performance indicators. When resource allocation and incomes of senior personnel in welfare agencies are linked to performance then there is an incentive to maximise performance. This can result in 'creaming' (McKinlay 1975, p. 365), eliminating or rendering 'invisible' cases that jeopardise the achievement of performance targets. Older people are particularly vulnerable to creaming, as they are likely to need more resources than other users over a longer period of time. They can effectively 'clog up' the system. McKinlay identifies four techniques for eliminating unwanted cases:

'Firstly the eligibility requirements for the agency's service can be constructed in such a way that the official can exclude the client on first encounter... Secondly after accepting a client, an official can prematurely terminate contact while at the same time giving token recognition to some problem... Thirdly an official may only recognize a highly segmentalized area of the client's social life as relevant to his agency, and disregard other spheres of activity or problems... Fourthly, and probably the most effective and frequently employed technique of invisibility is for some official to recognize related problems, yet abdicate responsibility by referring the client to another agency' (1975, p. 365).

At a system level such behaviour is irrational as it harms the very users who have the greatest need for care and support and ensures that that the most vulnerable users do not receive an appropriate and integrated service. However at unit level it is highly rational. It enables individual units to manage a potentially overwhelming level of demand and achieve their performance targets.

\section{Resources}

Much of the systemic irrationality of the current system can be related to the current mechanisms of resource allocation both in systems funded from general taxation such as the UK's NHS and those funded through social insurance such as the German and Austrian systems. In both cases, resources are separately allocated for health and social care with health care receiving the largest share. Little resource is specifically used to provide incentives for the provision of integrated care. Roth and Reichert note in their review of integrated care in Germany:

'Regulations for financing are a basic prerequisite for improving the coordination or integration of health and social services for older people. Connected with this are essential incentives for participant activities' $(2002$, p. 8). 
The separate funding of health and social care for older people in Germany is a serious impediment to integration, which as Roth and Reichert (2002) note can only be achieved through additional and targeted funding:

'To this extent, reforms to integrate health and welfare services must be founded on the integration of financing systems and the overcoming of institutional barriers, especially between outpatient and inpatient care, between health and welfare services, and between professional and lay care... Such approaches have not yet been developed in Germany, as already explained, and it seems that their way is still blocked by many insuperable obstacles and unsolved problems'. (pp. 30-1)

It appears then that while central governments exhort agencies providing health and welfare services to integrate their services, they may actually provide few financial incentives to encourage collaboration, and this factor represents a further impediment to achieving integrated health and social care.

\section{Professional expertise}

Professional expertise is one of the major assets of modern health and social care systems. Indeed systems are shaped by and based on areas of professional expertise. However reliance on such expertise can create impediments to integration especially when professional boundaries are aligned with and reinforce organisational boundaries.

While professionals may justify their status and control of resources in terms of their altruistic interests in providing services, the reality is rather different. In the welfare sector, it has been suggested that professionals have developed a dominant position through monopolisation of specific skills and knowledge, and by excluding competitors who can undermine their dominant position (Freidson 1970, Johnson 1972). Thus professionals establish and police boundaries that maintain their status and rewards. As McKinlay (1975) notes, one way of creating and maintaining status is to associate with high status clients. Thus while a profession is ideologically committed to serving all clients:

"In the competition for increased prestige, it may be that one way to advance one's claims is to seek a 'higher' class clientele, rather than being identified as a lower status servant of the poor" (1975, p. 364).

Such professional considerations may reinforce organisational tendencies to cream and to avoid or to pass older service users on to other agencies.

\section{Dysfunctional Confidentiality}

One tactic used by professionals to protect their status is to emphasise the privileged status of the relationship that they have with their clients or users, especially the confidentiality of this relationship. Confidentiality can be used to restrict the flow of information between professionals and agencies. This professional justification for the restriction in the flow of information can be reinforced by data protection legislation, which specifies that data obtained for one purpose and stored electronically should not be reused for another purpose. This is designed to protect the privacy of the individual but paradoxically in health and social care may increase intrusion into users' privacy as each agency and professional deprived of the information collected by other agencies needs to duplicate information collection and assessments. 
Such restrictions on the free and easy movement in information are increasingly seen as a major impediment to integration. For example in England, the Department of Health has identified such problems in the following way:

'Assessments are often duplicated with no coherent approach across health and social care services. This problem is exacerbated by the fragmentation of information systems, which unnecessarily duplicate information held about individuals. Failure to share such information can result in failure to deliver the best package of care. Care provided on the basis of assessment may not be well co-ordinated or follow the complex pathway that an older person might follow' (DoH 2001a, p. 24).

\section{Organisational Boundaries - Conclusion}

While professionals provide the key skills and expertise for the care and support of older people, they may also act as an impediment to the development of an integrated service. Professionals groups seeking to enhance their status may seek to avoid low status clients who are considered to be professionally unrewarding. It is no accident that in the medical profession, geriatric medicine is a low status specialty that is continually under threat, while in social work, child care and protection is the considered to be the area in which social work can use the full range of their professional skills, whereas when providing social care of older people many social workers consider they are being de-professionalised and their role is restricted to that of bureaucratic care managers who fill in forms. Furthermore competition between professions tends to reinforce boundaries between care agencies as professions strive to create and maintain professional empires. This tendency reinforces the tensions between agencies and in particular restricts the flow of information as each profession claims ownership of the information it has collected and uses.

\section{Comment}

Given the organisational complexity of health and social care systems for older people in all European countries and the incentives to and opportunities for organisations to cream to maximise their performance, it is perhaps hardly surprising that older service users do not receive seamless care and experience the system as highly fragmented. The inferior service which many older service users receive when compared to younger service users is a product of ageism, the assumption that older people are less valuable as citizens and will benefit less from the resources allocate to their care and support. It might be anticipated that professionals with their commitment to the interests and well being of their clients would actively counter ageism. While there is some evidence that some professionals do, there is little evidence that the majority of health and social care professionals have actively engaged in anti-discriminative practice. Older people are still often regarded as low status clients who do not enable professionals to use the full range of their skills and should be avoided or passed on as quickly as possible.

\subsection{Summary and comment: Impediments to Integrated Care}

Tudor Hart (1971) coined the phrase 'inverse care law' to describe one of the paradoxes that lies at the core of the health and welfare systems in contemporary late modern societies. This 'law' infers that, the greater the need a person or population has (for a service), the lower the delivery of service will be for that person/population. Integration of health and social care for older people presents an exemplar of the inverse care law. Older service users need more integrated services, their ill health is rooted in complex and interacting causes, if these causes are not identified and treated then change can be rapid and treatment urgent and expensive, recovery 
may be slow and partial necessitating long term health and social care. There is little evidence that the health and social care system has adjusted to or prioritised the needs and interested of older people. Instead, the increased pressure on resources combined with an increased emphasis of value for money provides agencies with strong incentives to avoid or pass on as quickly as possible older people. There is little evidence that the professionals employed by these agencies have sought to counteract these tendencies through anti-discriminatory practice. It is difficult not to conclude that the fragmentation and lack of integration of the health and social care system is the product of deep rooted ageism which has to date permeated the whole health and welfare system.

\section{APPROACHES TO INTEGRATED HEALTH AND SOCIAL CARE}

The diversity of definitions of 'Integrated Care' found across the 'Procare' national reports reflects the way that integrated care tends to be treated, especially in policy documents, as a selfevident concept that does not need definition or analysis. Such a taken-for-granted approach may be functional in policy statements that are aiming to construct a broad consensus and gloss over potential tensions but are not helpful to local service providers who are seeking to develop integrated services, or to researchers who are seeking to identify and evaluate integrated services. This section is designed to provide an overview of different approaches to integration and to identify the approach that will be the most productive of future research.

Since our interest in integrated care is grounded in concerns about the quality of services, a starting point for our analysis is a consideration of quality in health and social care. Donabedian (1980) has provided a framework for analysing quality that identifies three approaches: structure, process and outcome. 'Structure' focuses on the resources available to organisations and care providers. The 'process' of care involves the relationship between staff and users, and the approach taken to care delivery. 'Outcome' is more difficult to define, but relates to a change in the client's health status 'which can be attributed to antecedent health care' ( $p .83)$. Donabedian (1980) proposes a utilitarian definition of 'quality of care', suggesting that interventions which can be judged as effective and beneficial to the population and are affordable in broad terms demonstrate quality within care provision. He also argues that:

"...the attributes that are part of the quality of life - for example the maintenance of autonomy and self-respect - are also attributes of a desirable client-practitioner relationship and, in this way, become part of the definition of quality" (Donabedian 1980 p.30).

Since integration of services can be seen as a dimension of service quality, Donabedian's (1980) framework can be used to classify approaches to integrated care. We will first examine whether it is possible to identify structural approaches to integration before exploring process and outcome approaches. 


\subsection{Structural integration}

\section{Organisational structure}

The structural approach to integration involves bringing together staff and resources in one single organisation under a single unified hierarchical structure. Since such integrated organisations are usually located within the public sector and funded from public resources their creation, structure and functions require legal sanction. While such an organisation may be internally divided into functional departments, externally it presents as a unified service. Thus a key characteristic of an integrated organisation is a single point or portal of entry for potential users at which all their requirements can be assessed and an appropriate provision of services agreed.

In the United Kingdom the development of 'Care Trusts' provides one model of structural integration (Alaszewski et al 2003, pp. 19-20). Such Trusts are intended to be single organisations that provide community based health and social care to a given population, and this may be a targeted group (such as older people) within a given geographical area. However, to date, the model is tending to develop in the specialty of mental health rather than in older people's healthcare.

\section{Structure and technology}

Modern technology, especially information technology, can be used to create virtual organisations, that is, organisations which are formally separate but because they have full and rapid exchange of information, function as a single entity. In the Netherlands the 'One-Window Model' (Ex et al 2003, pp. 20-21) has features of the integrated organisation model especially with its emphasis on a single point of contact or portal of entry for older people who wish to access services.

'The Vraagwijzer-window (query-guide window)....is a central point where people may go and address their questions to an adviser in the area of care and well-being. People are served immediately, or are brought into contact with those that can help them on their way. This may concern application of rent subsidy, or the arrangement of an intake-interview at the RIO [Regional Assessment Board]. Sometimes these windows function as a gateway to the RIO's: clients may apply for an assessment concerning home care or admission to a nursing home' (Ex et al; 2003, p.21)

While the One-Window model focuses primarily on the point of access, it is clear from the account given in the Netherlands Report (Ex et al 2003) that it is intended to facilitate the development of a virtual integrated organisation for older people:

'The central issue is whether the query guide window, as a so-called 'frontoffice', manages to make effective contacts with various provisions and functions in the 'back-office': (in fact) the local service providers. The better the mutual cooperation between these providers, the better the chance that the query-guide window facility will succeed. And that is what finally constitutes both the field of tension and challenge (Congreskrant OL2000, 2002).'(Ex et al 2003, p.21)

\section{Comment}

The structural approach to integration centres on the creation of integrated organisations that bring together a range of services, resources and staff. While such organisations may function 
through distinctive departments, a key integrating feature is the provision of a single point of entry at which the range of an individual's requirements is assessed and arrangements made for the provision of these services.

\subsection{Joint working: Process-centred collaboration}

Process-centred integration focuses on caring activities rather than on the organisational context within which such activities take place and can be defined as:

'...collaborative actions or activity, undertaken between health and social service organisations and practitioners.... with the ultimate aim of providing an improved service to the client or patient' (Hiscock and Pearson 1999, p.151).

As Wildavsky noted in 1979, there is universal support amongst service providers that they should 'contribute to a common purpose at the appropriate time and in the right amount to achieve co-ordination' (p. 132) but that organisational and professional boundaries create major impediments. Similarly, Donabedian (1980) noted that:

'....with several providers of care, failures in continuity and co-ordination are more likely; these attributes thereby become more important as determinants of the quality of care' (p.18).

The process-centred approach to integration focuses on ways of overcoming impediments through the use of incentives or closer working between professionals, and there is evidence of this approach across Europe, and specifically in France and Greece where a model of 'gerontological teams' can be identified.

In France, the use of the term 'co-ordination' is derived from the French government's promotion of this form of co-operation between professionals since 1982 . Since the 1980's, a lot of co-ordination structures have employed a co-ordinator, or "case manager". Co-ordination is a central aim of French gerontological policy - for example, there is a 5-year programme for the creation of 1,000 "Local Information and Gerontological Co-ordination Centres" (2001-2005).

The co-ordination model aims to achieve integration in all three stages of Donabedian's (1980) model. Structural integration is managed by the development of a single access point (or office) that handles all initial enquiries from older people and their carers. Process integration is achieved through fostering joint working, and the intention is that person centred and 'seamless' services will be the outcome of the 'co-ordination' approach. In France, the word "coordination" means a more flexible and horizontal arrangement than the term 'integrated care' suggests. The co-ordination is a voluntary organisation of professional people who pool their means and resources to develop information, social or health care, and prevention services designed to resolve complex or urgent problems that have been identified as priorities over a given geographical area, according to criteria decided in advance on a consultation basis. So the number of organisations involved in co-ordination can vary over time (see Frossard et al 2002).

\section{Incentives for integration}

There is a major body of literature that explores the use of incentives to facilitate interagency collaboration. Benson (1975) has argued that health and social agencies form parts of local networks and these networks are held together by mutual dependencies, because individual agencies hold resources that other agencies need to accomplish their tasks. This insight provides 
the basis of interventions designed to increase dependency and integration through the manipulation of resource allocation.

In insurance-based systems with their strong emphasis on resource allocation and economic incentives, such approaches are essential. In Austria, progress towards integration has been made through the development of a specialist fund, the 'long-term care allowance', which provides one incentive for the development of more integrated care:

'As a first step, the formerly scattered and unequal cash benefit schemes for frail persons in need of care were comprehensively regulated within the "Bundespflegegeldgesetz" (Federal Long-Term Care Allowance Act), which came into force on July 1, 1993. According to this law, all people with disabilities and/or chronic illness who are in need of at least 50 hours of attendance and care per month are entitled to a long-term care allowance' (Grilz-Wolf et al 2003 p. 7).

\section{Interdisciplinary working and teams}

An alternative approach to process integration is closer working between the professionals engaged in providing support for older people. A common theme running through the PROCARE reports is integrated care as interdisciplinary working or team working. In most countries in the PROCARE study there is pressure for and evidence of inter-professional working and the development of inter-professional teams. For example, the Danish Report identifies the formation of multi-professional geriatric teams. The hospitals have led the way in the formation of these teams and professionals employed by the hospital form the core team, which usually has a doctor, a nurse, and secretary. In addition some teams include therapist, occupational and physiotherapists and social workers. The most developed teams include local authority social care staff as well as hospital staff. The aims of the teams are:

'To ensure a coherent treatment and follow-up after discharge from hospital... to treat the elderly as close as possible on own surroundings and prevent admission to hospital or re-admission. The team is supposed to ensure a co-ordination of the effort for the elderly between the [hospital and local authority] sectors. The target group for the geriatric teams is elderly with complex health problems and/or loss of function' (Colmorten et al 2003, p. 16).

In the United Kingdom there has been consistent pressure on individual professions to work collaboratively or to participate in team working. It is therefore hardly surprising to find that in the UK, joint and team-working form a prominent part of current initiatives in integrated health and social care, especially in the development of intermediate care. For example, the central feature of Community Assessment and Rehabilitation Teams (CART) is multi-professional working:

'This service model was one of the earliest developments in intermediate care, with many schemes set up during the mid 1990 s, prior to the 'winter pressures' funding (Vaughan and Lathlean 1999). With respect to joint working, the important difference is that a multi-professional team is central to the service design and is housed in one location, usually in a health service setting. CARTs take referrals both from hospital and community settings, both pre-admission and post-discharge. The intention is that the intervention be available before a point of crisis requiring hospital admission is reached. The teams are usually made up of nurses, occupational therapists and physiotherapists, and should conduct an 
integrated assessment of the individual. One professional will take the lead role, depending on which therapy is most needed - for example, if the person has had a number of falls, and the assessment suggests that physiotherapy would be the most appropriate intervention, the physiotherapist will take on the lead role of assessment and evaluation' (Alaszewski et al 2003, p.19).

\section{Comment}

Process-centred approaches focus on the ways in which care activities are integrated. They are less concerned with the agencies or organisations that form the basis of the structural approach. They by-pass the organisational level by focusing either on the overall ways in which resources in the system can be used to create incentives for the integration of care activities, or more directly on the development of inter-professional teams bringing together the skills and expertise from different agencies into one integrated team.

\subsection{Person-centred, seamless care}

As Donabedian (1980) notes, approaches that discuss quality in terms of either structure or process are limited as they are describing the means not the end. The 'ends' of health and social care systems are their outputs, the care and support which older people receive. It is self-evident that health and social care systems for older people are designed to improve the lives of the people that use them. Traditionally, health services have focussed on creating functional improvements in health of service users. It is possible to apply this type of approach to services for older people using measurement instruments such as the Minimum Data Set (MDS) (InterRAI 2001) which assess individual functioning. However, because these instruments are designed to assist professionals in complex assessment, rather than to identify the clients' experience of receiving care, there is a risk that the key features of integrated care may be missed if a quantitative or standardised approach to evaluating integrated care is applied. A central theme found across the PROCARE participating countries is that integrated care may be defined by the way in which users experience it. They should experience it as continuous or seamless care that does not have gaps, waiting or overlap conflict between different components. While such care should help older people live a more effective life, improvements in functional ability may not necessarily be the most important outcome. For example, older people suffering from dementia or dying may benefit most from services that are flexible and adjust to changing circumstances.

\section{Seamless care}

Thus integrated services should be those that provide continuity of care from both subjective and objective perspectives. A recent review defined aspects of integrated care delivery as follows:

'Experienced continuity: The experience of a co-ordinated and smooth progression between services'

'Flexible continuity: To be flexible and adjust to the needs of the individual over time' (Freeman 2000, p.23)

In some of the PROCARE reports it is possible to identify this approach to integrated care with an emphasis on either seamless care or responsiveness to the needs of individual service users. For example, the Finnish Report emphasises 'seamless' care: 
'Seamless service chains are defined as an operating model, where the services received by a client... within social and welfare and health care services... are integrated into a flexible entity which will satisfy the client's needs regardless of which operating unit provides or implements the service' (Ranta 2001, from Salonen and Haverinen, 2003, p.7)

While the Dutch Report focuses on responsiveness to user demands:

'Demand-driven care....simultaneously means integrated care for, when the requests and needs which the client may experience in various areas are met, integrated care is provided' (Ex et al 2003, p. 22)

\section{Models of seamless care}

While most of the models identified in the PROCARE reports are 'structure' or 'process' oriented, it is also possible to identify models whose design appears driven by the pursuit of 'seamless care' as an outcome. The Danish report provides one exemplar of this model, which is the service provided by the municipality of Skaevinge. The starting point for the integrated service was the existing specialised services provided by five separate departments within the municipality including one for residential care managing a large nursing home, one for home nursing, one for home help, one for health care and one for social work support (Wagner, 1994). These health and social care components were integrated into a single service providing integrated health and social care up to 24 hours a day to older people in a given geographical area. Within this service there are autonomous multi-professional groups. These groups share a common value system and goals, i.e. facilitating user self care, and can respond rapidly to changes in user requirements. This may mean that an older person can be nursed through an acute illness at home, thereby avoiding the upheaval of hospital admission. All citizens are eligible and might have equal access to provided health and social care, irrespective of living at home or on institution.

The Skaevinge scheme is based around a former nursing home, which was converted into individual apartments without having to change the original layout. At the same time a health centre was established, putting together home nursing, public health nursing and day centre under one roof. Here, the various professional and technical groups work closely together for the first time. The centre directs its attention not only to the 63 older people who live in the new apartments but also equally toward other older people in the municipality (see Colmorten et al 2003, pp.19-20).

\subsection{Summary and comment - Approaches to integrated care}

While 'integration' forms an important part of the policy rhetoric in all European countries that form part of the PROCARE programme, it remains possible to identify a number of different approaches. Since the fragmentation of the delivery into competing health and social care organisations is one characteristic of all the countries, it seems self-evident that structural change, that is, the creation of single agencies providing both health and social care is one possible solution. Indeed in the UK some commentators see the creation of integrated "Care Trusts' as the way forward. However, given the time and energy absorbed by such reforms and the institutional inertia evident in some countries (e.g. Germany), an alternative approach it to focus on the activities of caring either by providing incentives for integrated working (as in the Austrian long-term fund) or through encouraging the development of inter-professional care teams (such as the UK's Community Assessment and Rehabilitation Schemes). Both 
organisational restructuring and the integration of care activities through interdisciplinary teams are a means to an end, namely the development of integrated care. It is possible to recognise a third approach, which focuses directly on the provision of seamless or continuous care. Such a person-centred approach is typified in the 'Skaevinge' 24-hour health and care scheme in Denmark.

\section{ASSESSING INTEGRATION: ORGANISATIONAL AND PERSON-CENTRED OUTCOMES}

Since integration of services for older people is likely to be beneficial, all governments in the PROCARE study had policy statements that endorsed it, and most supported this with legislation and in some cases there were also resources specifically allocated to supporting integration. In such a context it is important to assess the extent to which reality of service provision matches the policy rhetoric.

To do this it is important to identify tools that assess the nature and degree of integration. Since we have identified different approaches to integration it should follow that we are also able to identify different approaches to its evaluation. In this section we will examine three approaches starting with those that seek to measure integration in terms of service outputs (3.1). We will then consider those that focus on the objective and subjective experience of users (3.2) before finally considering approaches that take a broader societal perspective considering issues such as social integration (3.3).

\subsection{Care pathways and need: the systems approach}

The 'service output' research or audit approach to evaluation is likely to be predominant during the process of managing effective service integration, although it does assume that integration can be assessed in terms of measurable outputs. It is possible to consider outputs in terms of process, i.e. the continuity of care, and in terms of direct impact of users, i.e. changes in users' levels of functioning and health.

\section{'Continuity of Care' and 'Care Pathways'}

It is likely that an expected outcome of integration might be improved continuity of care, but in practice, measurement of 'continuity' can prove extremely difficult. Freeman (2000) acknowledges that continuity is an ambiguous and contested concept, and identifies two contrasting dimensions of continuity. One dimension concerns the stability of the caring relationship with the minimisation of disruption to this relationship. This type of continuity takes several forms:

- Longitudinal continuity Care from as few professionals as possible consistent with other needs

- Relational or personal continuity Providing one or more named individual professionals with whom the patient can establish and maintain a therapeutic relationship

- Geographic continuity Care is given/received on one site.

The second dimension addresses mechanisms that provide continuity by counteracting disruption of care especially across organisational boundaries and include:

- Continuity of information Excellent information transfer following the patient

- Cross-boundary and team continuity Effective communication between professionals and services and with patients. 
One way of overcoming such ambiguities is to focus on the health and social care provision within a locality as a single system and then examine the pathways that individual users take through this system. Soft systems technologies developed in 'Operational Research' (the use of mathematical or computer models to analyse an organisation's operations) have been used to simulate such pathways. If the system is integrated then individual users' path through the system should be smooth and direct without blockages and delays, and individuals being cared for in each service should meet the criteria for that service.

This approach is clearly articulated in the UK's Department of Health review of discharge from hospital to community services. The review stresses the importance of a systems approach built around the needs of users:

'Whole system working does not have restrictive service boundaries-it puts the individual at the centre of service provision and responds to their needs... The whole system is not simply a collection of organisations that need to work together, but a mixture of different people, professions, services and buildings which have individuals as their unifying concern and deliver a range of services in a variety of settings to provide the right care in the right place at the right time' (DoH 2003, p. 15)

If health and social care agencies do function together as a system then individual users should have smooth pathways or journeys through the care system following 'agreed and explicit routes' (DoH 2003, p.xi) in which the services provided are appropriately adjusted as their needs change. In particular there should be no delays or backlogs that prevent a person moving on when they are ready. The 'Procare' national reports suggest that there are waiting lists for social care across many northern European countries, including the UK, the Netherlands and Denmark. The Department of Health summarises the UK position in the following way:

'The research literature on hospital discharge goes back at least thirty years and there is remarkable consistency in the research findings, which continue to report on the breakdowns in routine discharge arrangements. In particular, older people make up a disproportionate number of those whose discharge from hospital is delayed and who are waiting for other services' (DoH, 2003, p. 1)

In Denmark, the 'Skaevinge' project has contributed to the development of older people's care across the country (see section 2.3). A ten-year local evaluation of the project produced the following observations:

- Older persons believed that their health status had improved. They were asked in 1985 and again in 1997.

- Even though the number of persons with 75 years or more had increased by 30 per cent, the operational expenditures have decreased.

- There is the same amount of staff in 1996 as there was in 1986.

- The preventive care efforts have entailed a surplus of capacity, which among other things have been used to establish acute beds and rehabilitation places in the community to prevent unnecessary admissions to hospitals.

- The use of bed days at hospitals have been reduced by 30-40 per cent for all citizens in the community

- The municipality has not had waiting days at hospitals during 10 years for older people whose hospital treatment is completed. 
- There is no waiting time for (supported housing) apartments in the health centre or for home help.

- The use of and expenditure to sick insurance is less than in the rest of the county.

These findings are believed to result from the emphasis placed by the municipality on preventative care, flexibility and individualised health and social care (Wagner 2000).

Assessing need and measuring the impact of services

Given the centrality of need to the operation of health and social care agencies, there are a plethora of different approaches available for the assessment of individual need. Indeed in the UK the government has sought to reduce the confusion by supporting the development of a single integrated assessment though as yet has not commended a single model (DoH 2002b). Most of these assessments focus on the individuals' functional abilities, i.e. their ability to perform activities of every day living such as walking or maintaining bowel or bladder control, and identify deficits. These deficits can be used as an indicator of a person's need and an overall assessment can indicate their level of functioning and need. One example of such an assessment is the Minimum Data Set (MDS). This set of instruments has been developed to enable comprehensive assessments of older people to be undertaken (and repeated as indicated) in a number of settings. It is now used in a variety of countries including Canada, Japan, the UK and Italy (InterRAI 2001).

Instruments that aim to assess need such as the MDS could potentially be used to support the integration of health and welfare systems. Different components of the system should have different functions and therefore should be designed to meet different needs. One approach to evaluation is to examine the extent to which the needs of the service users actually match the needs criteria specified by each service. A study of intermediate care in East Kent (UK) found a mismatch between the needs criteria of services and characteristics of older people actually being treated within the service:

'This section shows that each of the intermediate care services were providing for people who did not meet all their criteria. CART [Community Assessment and Rehabilitation Teams] admitted people not meeting the Rehabilitation Potential criteria, Recuperative Care admitted people not meeting the Mobility criterion and Day Hospital admitted people not meeting the Rehabilitation and Cognition criteria... some people admitted to [hospital rehabilitation] wards may have been potential candidates for ICS [Intermediate care Services]' (Carpenter et al 2002, p. 57)

\section{Comment}

The effective assessment of need opens up the possibility of assessing the health and social care agencies as systems in terms of their outputs, in particular the impact they have on the functional ability of older people. For example the MDS is currently being used to evaluate home care for older people in a number of European countries, and also in North America and Canada. However such an approach assumes that main purpose of services is to improve the functional ability of people using them. For some services and for some users there may be other more important purposes, for example the purpose of palliative care may be to help individuals die with dignity and for older people with dementia minimising the impact of mental changes may be crucial. The needs approach tends to emphasis individual deficits, and it is also an approach in which the individuality of service users tends to get lost in the aggregation, for example when there are delays in discharge, individual older people are classified as 'bed blockers'. The 
individual experience subsequently tends to be lost and the overall assessment of integration tends to be in utilitarian terms, i.e. aggregation of the benefits of the defined population. In the next sections we consider approaches that focus more on the individual and his or her experience of integration, and it is this aspect of integrated care that is to be explored during the empirical phase of the 'Procare' study.

\subsection{Risk and integration}

An alternative way to thinking about the nature of the relationship between service users and health and social care agencies is in terms of risk rather than need. As Kemshall notes in a recent study:

Risk, particularly an individualized and responsibilized risk, is replacing need as the core principle of social policy formation and welfare delivery (Kemshall 2002, p. 1).

While the needs approach focuses primarily on functional deficits, a risk approach focuses on the change that an individual is likely to experience. In its narrowest form the risk approach is concerned with identifying and protecting individuals from harm but in its broader form it is concerned with individuals' own aims and experiences. We will deal with the narrower harm minimisation approach first.

\section{Harm minimisation and the safety culture}

The 'harm minimisation' approach was initially developed as a pragmatic response to serious problems that did not seem amenable to the more traditional 'needs approach' (Alaszewski et al, 1998, p. 142-143). The most obvious example is drug use. The recognition of HIV/AIDS resulted in a shift from identifying drug use as a behaviour that needed to be eradicated through police and other action to developing strategies to minimise the harmful consequences of drug use through needle exchanges and other schemes (Strang and Stimson 1990, p. 330). The overall success of this approach is judged in terms of the reduction of harm.

Integrated care can be assessed in terms of harm minimisation. It is possible to examine the ways in which health and welfare agencies contribute to the safety of the older service users by reducing the overall incidence of harm. For example, in Denmark, all municipalities are obliged to conduct two preventive home visits a year to citizens aged $75+$ in order to identify and reduce risk factors in the home of the elderly person, and 85 percent of the municipalities fulfil that obligation. The presence of a proactive preventative system of this nature is unique to Denmark, although similar projects are present, albeit less widespread, in other countries. While the harm minimisation approach provides a more dynamic and more focussed way of assessing the impact of integration on individual users, it is still essentially utilitarian, assessing and aggregating collective benefit in terms of the harm prevented. The individual experience still remains elusive.

Some commentators are critical of the risk approach as it tends to emphasise the vulnerability of service users to harm and can be seen as fostering a protective paternalist approach to service delivery that undermines the autonomy and independence of older people. For example Alaszewski and Manthorpe note the tendency of risk management to creative restrictive services which:

'..exaggerate the vulnerability of older people, restricting them unnecessarily and resulting in over protection' (2000, p. 197). 
Such restrictions tend to occur when risk is equated with danger. Such a narrow restricted approach treats risk assessment and management as a technical activity of identifying and counteracting hazards such as the various factors that may result in falls. Little attention is played to the broader and far more complex issue of values. Implicit within the approach is a set of values, for example that the main priority of services should be to protect individuals from physical harm especially death. These values are deeply embedded within professional practice and ethics and in the United Kingdom, following high profile scandals in which services have failed to protect vulnerable individuals, have been given formal government recognition as the basis of clinical governance. It seems self-evident that harm minimisation is socially beneficial. However, if we adopt a broader definition of risk as:

'The possibility that a given course of action will not achieve its desired and intended outcome but instead some undesired and undesirable situation will develop' (adapted from Alaszewski and Manthorpe, 1991, p. 277),

then we can consider what is desired and factor in personal values, especially those of users and carers, which allows a richer picture to develop. Studies of users and carers indicate that they are undoubtedly aware and concerned about the possibility of harm but may not give it the same overriding priority as professionals and agencies (Heyman 1998, Alaszewski et al 2000, pp. 4770). They may wish to balance harm minimisation against other personal priorities, such as independence or privacy.

If this approach is taken seriously then it is only possible to assess the full extent of integration by considering how and in what ways agencies assist (or hinder) users and carers achieve their desired goals. Thus the starting point has to be users and carers desired and intended outcomes, and evaluation must include their experience of services and the ways in which they perceive their interaction with services assists or hinders achievement of their goals. Any study that addresses these issues will need to have a strong qualitative component using naturalistic methods such as in-depth interview and observation (Ong 1993, pp. 57-63, Murphy 2001). It is difficult to see how standardised assessment instruments that seek to identify need, or structured patient satisfaction questionnaires, can capture the complex and dynamic nature of user and carer interaction with services.

\section{Comment}

The assessment of integration in older people's services still tends to be very much within the traditional 'need' paradigm, in which the emphasis is on the functional deficits of individual users and the ways in which services respond to such deficits. The development of risk-based approaches facilitates a broader, more dynamic approach. Harm minimisation identifies the factors that make older people vulnerable, (e.g. falls), and can be used to evaluate integration in terms of the overall minimisation of harm. The harm minimisation approach still tends to aggregate individuals into 'at-risk' groups and gives precedence to agency and professional values. It needs to be expanded to take account of the values of older people and their carers if it is to form the basis fully person-centred approach. There is considerable policy rhetoric about developing person centred care but it takes the form of providing information to users, rather than adjusting the service to the wishes of the user. For example, in the UK's National Service Framework discussion of person-centred care, communication is a way process:

'Information should be provided at key points in the pathway, or stages of treatment. Many older people live with long-term illness, frailty or disability; if 
they have appropriate information, they will be better able to participate in managing their own condition and lives' (DoH 2001a, p. 27)

Although elsewhere in Europe there is evidence of programmes to encourage more active consumerism in older people, including the provision of internet technology in older people's homes or facilities (E.g. Ex et al 2003, p.17), this remains a one-way process where older people are the recipients of care, rather than empowered to take part in care provision processes. A recent UK study identified that older people feel disadvantaged by the lack of information about services, and noted that 'the concept of advocacy was rarely recognised amongst older service users' (Joseph Rowntree Foundation 2003).

The UK 'single assessment process' guidance does specify that user's perspectives and expectations must be recorded ( $\mathrm{DoH} 2001 \mathrm{a})$. But as yet it not clear that tools currently being used actually include these perspectives and if they do there is little evidence that the information is being used to shape care or evaluate services. The questions that lie at the heart of the personcentred approach are relatively easy to articulate, for example: 'What do older people and their carers want, and do they get this?' To answer such questions one needs to access the perceptions and experiences of older people and their carers. This requires the use of relatively costly and labour intensive research methodologies and at present there is little evidence of substantial investment of research time into these methodologies. There is also an issue of the scope of the questions: Should the assessment be restricted to the relationship between users, cares and services or should it take into account the whole of their life experience? It is to this issue we turn in the next section.

\subsection{Collective or community perspectives: social inclusion}

While health and social care agencies focus on their own specific tasks, it is possible within some countries to identify a broader policy agenda that addresses the ways in which vulnerable and deprived individuals and groups relate to the wider society. This policy agenda is driven by concerns that certain groups do not engage with civil society and that this disengagement represents both wastage of resources and also a threat to the society. For example if grievances are not expressed through the normal political system they may be articulated as destructive behaviour directed either at the self (e.g. suicide or self-harm), or others (e.g. vandalism and civil disorder). These anxieties are long standing and can be traced back to work of $19^{\text {th }}$ century sociologists. For example, Durkheim (1933) identified the growth of 'anomie', the declining moral and social integration of individuals in society. In current terminology this process is referred to as 'social exclusion'.

\section{Social inclusion and older people}

The measures to counteract social exclusion focus on individual engagement in social networks, to encourage participation in society as a full citizen. In the UK government, there is a social exclusion unit (SEU) located within the Cabinet Office whose function is to ensure that there is an integrated government response to exclusion or in the Prime Minister's terminology, a 'joined-up solution to joined-up problems'. The prime focus of the SEU is on the exclusion of younger people as they appear to be seen both as the most vulnerable and also the most dangerous. However since older people are also citizens, the general measures designed to improve social integration through community building such as neighbourhood renewal include them. 
It is clear that neighbourhood renewal is based on integration of all services provided within a neighbourhood and that it is not only designed to improve service but also to increase engagement. In the first issue of the Social Exclusion Unit's (SEU) review, there is an interview with Joe Montgomery, Director of the SEU's main programmes. He describes the function of the SEU strategy in the following way:

'Our work is about tackling the root causes of deprivation through improvements to mainstream public services, and the involvement of people in their own communities. By driving up standards in areas such as education and health, we are focussing efforts on changing the prospects of people who live in deprived neighbourhoods... We also support communities by putting them at the heart of the neighbourhood renewal process... Local people and organisations can easily identify the problems they face and propose solutions. Our approach is about removing barriers so that local people can also ensure these solutions are implemented. In many ways, the Government's success will be judged by the success of neighbourhood renewal. The proof will be that in communities and in families we see real improvements across health, education, employment and quality of life' (Inclusion News, 2003).

It is perhaps another example of institutional ageism in the UK that the Social Exclusion Unit does not have any programme that explicitly address the social exclusion of older people. Social inclusion is addressed in the National Service Framework but in a rather weak form as 'The promotion of health and active life in older age' (DoH 2001a, p. 107). The main focus is on health promotion designed to minimise decline. Wider participation is briefly considered but only in terms of safety and risk and the main responsibility for social inclusion is given to other local government agencies:

"A neighbourhood that is perceived to be safe will enable older people to feel safe in their own home, and able to go out at will. The NHS and social care agencies should collaborate with local community safety partnership and other communitybased activities...Access to wider community facilities, libraries, education, and leisure for example, will enable older people to participate in and contribute to society' (DoH 2001a, p. 112).

\section{Assessing social inclusion}

Given the relative invisibility of older people in the social inclusion debate, it is difficult to identify and develop approaches that assess the extent to which service integration actually contributes to inclusion of older people within society. Therefore at this stage we are speculating on the type of information that might be required. One approach might be to focus specifically on the older person/community relationship and the other to take a more holistic approach.

An approach which focuses on the older persons community relations would seek to explore the extent to which services support older people in accessing the wider community physically and socially. For example, does domiciliary care provided by health and social service agencies merely 'warehouse' older people at home keeping them clean, fed and safe - or does it enable them to maintain and develop their social inclusion by helping them to physically move outside their home using local facilities, thereby maintaining their social networks?

Part of the problem with any framework that is used to assess the effect of services on older people is the variety of contexts in which it has to be used. For example the situation of an older 
person who has just been discharged from hospital following a bout of pneumonia is very different from an older person who is developing dementia and this in turn is different again from the needs of an older person dying of cancer. Both the needs and risk approach deal with this difference through assessing need or risk and then assessing how far services address either the need or risk. It is not clear how a social inclusion approach would take into account such variations. One possible solution is to by-pass the issue by focussing directly on a more holistic assessment of the individual, especially whether individuals are thriving or flourishing.

This approach has been applied successfully at the other end of the life course, to young babies. In childcare services social workers and other professionals have a legal duty to integrate their services to ensure children are protected from harm and to intervene when they judge there is a significant risk of harm. While some evidence such as physical bruising or fractured bones is a strong indicator of harm, in many cases it is absent or forms part of an overall picture. The holistic assessment of a harmful relationship identifies:

'Significant impairment of the child's health or development, including nonorganic failure to thrive' (Lyon and de Cruz 1993, p. 6)

Thriving is contextually defined. In the case of young babies it can be defined in terms of physical development:

'Babies have an expected normal level of growth (weight and length), which is based upon their weight and size. Those that fall well below this expectation, with no apparent physical explanation, are considered to be causes for concern, and neglect (both physical and emotional) is thought to be a likely cause of this' (Corby 1993, p. 46-7).

While this approach to assessment developed as a technical and pragmatic response to a socially sensitive situation, it can also be seen as be seen as an example of an ethical approach to assessment that has a long and complex history (Alaszewski et al 2000, pp. 171-175). Aristotle, the Greek philosopher, argued that ethics is concerned with judging what is 'good' and that one way of defining goodness is in terms of the purpose or end of an action or thing. Almond, a contemporary philosopher interested in medical ethics, defines ethics in the following way:

'The notion of flourishing... derives from the idea that every kind of object has its own essential end or function... a musical instrument is for making music. The Greek word for excellence, arete is the word we translate as 'virtue'. So the excellence of a chair, a knife, a musical instrument, consists in it's being able to fulfil its essential function (ergon) well. We might speak of an ideal chair, or an ideal knife, with approval. The idea that this generates, then, is that for an object or a creature to flourish, is for it to be in a state or situation that allows it to fulfil its essential function well. As far as human beings are concerned, this may well be a matter of displaying the traditional virtues' (Emphasis in the original, Almond 2000, p. 100).

If this approach were applied to assessing integrated services then it would need to start from the specific context. For example in terms of dying it may be possible to define a 'good' death as one in which an individual dies with dignity. Part of this process may be related to the dying person's preference for where death should take place, part would relate to the effective management of physiological processes such as pain and part to the social context that are 
culturally appropriate for the dying person, the family and friends he or she wishes to have involved and his or her involvement in social processes after death such as funeral arrangements. Thus a holistic assessment of dying would assess the extent to which integrated services had contributed to or hindered a good death. Similarly this approach could be applied to assessing the effectiveness of rehabilitation after a stroke. Part of rehabilitation relates to the improving physical functioning, however a crucial element is the way in which an individual normalises their life and recreates their personal identity though social integration. Again, holistic assessment would measure the overall contribution of services to the process of rehabilitation.

\subsection{Summary and Comment: Assessing Integration}

There appear to be no good reasons why older people should not be included within policy development designed to increase the engagement of vulnerable individuals within mainstream society, yet barriers to the inclusion of this group clearly remain. If person-centred policies are taken seriously then they imply integration of co-ordination of all locally delivered public services: health, social care, police and housing to name just a few. The services will be increasingly judged not just in their own functional terms but how they contribute to the broader social goal of social inclusion. As yet there are few measures to assess the ways in which services contribute to social integration. We would suggest that the virtue approach provides the conceptual basis for a holistic person-centred approach to such assessments.

While it is important to analyse and describe integrated care, it is also important to assess the effectiveness of different models. There are a number of different approaches each with its own strengths and weakness. Just as the process of defining and understanding 'Integrated health and social care' is in its early stage, so too are methods for evaluating ways of collaborative working. These methods of evaluation can be summarised as follows:

\section{Continuity of care}

This approach concentrates on the care system and examines whether the components work together to provide a smooth pathway or whether there are delays especially at common boundaries, for example between acute hospitals and community services. A systems approach can be used to examine whether individuals are appropriately being cared for in specific parts of the service by comparing the admission criteria for a service with the specified patient needs. This approach is being developed using well-established operational research methodologies and does facilitate modelling of care systems. However it does also aggregate individuals into groups so it is not clear how individuals experience and are affected by the system.

\section{Meeting needs}

Since it can be argued that health and social care systems exist to meet the needs of the individuals that use their service, it seems self-evident that integration should be assessed in terms of whether collaboration between services leads to a situation where health and social care agencies can meet these needs more effectively. A standardised approach to this is now well established and several European governments have invested considerable resources in developing tools and data systems. However, there remain a number of challenges to this approach. Not only does this tend to aggregate individuals into groups, it also tends to focus on their negative aspects, things they cannot do without help, and information tends to be decontextualised. Furthermore it is difficult using this approach to disaggregate the effect of integration from that of individual services. 


\section{Harm minimisation}

This builds on current interest in risk assessment and management and focuses on identifying and counteracting causes of harm and measuring the impact of interventions in terms of reduced harm. Since such interventions rely on integrated action by health and social care agencies, harm minimisation could be used as an indicator of integration. At the moment this approach has only been applied in the UK in specific areas such as falls, an area highly relevant for older people. In Denmark, there is evidence that a proactive visiting service is being supported by government and implemented across the country, so that all individuals aged over 75 receive two home visits a year, specifically to identify and reduce risk factors, and this includes social, emotional and physiological risk factors which may indicate falls, depression or social exclusion (Colmorten et al 2003). The problem associated with this type of service is that with the emphasis on overall levels of harm, the approach is built on the professional's value system, which may privilege harm minimisation over the older person's own goals and values.

\section{Person centred risk evaluation}

The 'risk' approach can be used as the basis of a person centred evaluation if the values and goals of users and carers are acknowledged and a serious effort is made to examine whether services are recognising individual difference in values and enabling individuals to achieve their personal goals. While there is considerable government rhetoric about person-centred services, there is less evidence of a developing technology for person-centred assessment of integrated care. There are intrinsic difficulties to developing person-centred assessments. They will need to be grounded in naturalistic research methodologies that are expensive to apply universally. Furthermore such methodologies are not familiar or well understood within the biomedical establishment that currently dominates the funding of health and social care research.

\section{Social inclusion and access to the community}

If older people are to have full rights as citizens it is important that they are able to access all community facilities and to establish and maintain social networks. Thus integration can be assessed in terms of how it enables older people to overcome the physical and social impediments to maintaining social networks. While the research tools to examine the ways in which older people participate already exist, it is not clear that have yet been used to address this specific issue.

\section{Holistic assessment based on virtue ethics}

Social inclusion can be seen as a means to an end, as a mechanism for ensuring older people have flourishing lives. It is possible to use virtue ethics to develop a context-sensitive personcentred methodology for assessing the contribution of integrated services. In some areas such as palliative care or stroke rehabilitation the outlines of this approach can be sketched in, however substantial work is needed if this approach is to be more generally used.

\section{CONCLUSION}

As welfare systems mature in the European Union it is possible to identify a new post-Fordist approach. The initial Fordist stages of the welfare state were characterised by a standardised approach and fragmented service delivery in which the each agency sought to deliver standardised services at the lowest possible cost. This provides incentives for agencies to reduce their costs by passing on difficult and costly cases, which usually includes older people. In such systems individuals, especially vulnerable individuals with complex need are not likely to receive an integrated service that provides continuity of care. The post-Fordist system is intended 
to radically change individual experience of services so that users experience a seamless services that adjusts flexible and quickly to their changing needs and wants.

Given the importance of integration and partnership to current welfare reforms, it is hardly surprising that there are a variety of initiatives designed to enhance integration. An obvious starting point is the creation of new agencies combining both health and social care functions, yet the costs of such structural reform, both in terms of finance and of wide ranging organisational change, are often judged to be prohibitive. A further alternative is to use information technology to effectively create a virtual agency whose components share information and decision-making. Structures are of course a means to an end, and therefore some models by-pass structural reform, concentrating instead on integrating processes either by providing incentives and additional resources or by encouraging teamwork that brings together information, expertise and decisionmaking. Finally some models concentrate directly on seamless care by either providing a single access point through which users can access all services or guaranteeing comprehensive 24 hours care.

Since all countries in the PROCARE study are committed to some form of integration of health and social care, it is important to assess the extent to which the different models being used actually achieve integration. However just as there are different models of integration so there are also different ways of assessing integration. Three of these approaches fall within a utilitarian framework assessing the overall system or aggregated benefits or gains from integration:

- 'Continuity of care' identifies the delays, blockages and losses which result from lack of integration

- The 'needs approach' examines the ways in which integration contributes to meeting need, and

- The 'harm minimisation' approach examines the ways in which integration can ensure safety and reduce harm.

The other three approaches are:

- The 'person-centred' approach, which explores the individual experiences and benefits of integration. A 'person-centred risk evaluation' model can also be identified, and this examines the individual's personal attributes and risk factors, and the extent to which integration enables individuals to remain safe and avoid harm.

- The 'social inclusion' approach, which examines the way in which integration enables individuals to fully participate in society, and finally

- The 'virtue ethics' approach, which considers the ways in which integration contributes to thriving old age. 


\section{REFERENCES}

Arcares (2002) Zorg en huisvesting. Arcares, Utrecht.

Alaszewski, A., Baldock, J., Billings, J., Coxon, K., and Twigg, J. (2003) Providing integrated health and social care for older persons in the United Kingdom Centre for Health Services Studies, University of Kent, Canterbury, UK.

Alaszewski, A., Alaszewski, H., Ayer, S., and Manthorpe, J. (2000) Managing Risk in Community Practice Balliere Tindall, Edinburgh.

Alaszewski, H. and Manthorpe, J. (2000) Older People, nurses and risk, Education and Ageing 15, pp. 195-209.

Alaszewski, A., Harrison, L. and Manthorpe, J. (1998) Risk, Health and Welfare Open University Press, Buckingham.

Alaszewski, A. and Manthorpe, J. (1991) 'Measuring and Managing Risk in Social Welfare - A Literature Review' British Journal of Social Work 21, pp277-290.

Almond, B. (2000) Commodifying animals: ethical issues in genetic engineering of animals Health, Risk and Society 2, pp. 95-105.

Benson, J. K. (1975) The Inter-Organisational Network as a Political Economy, Administrative Science Quarterly, 20, pp. 229-249.

Bowling, A., Bond, M., McKee, D. et al (2001) Equity in access to exercise tolerance testing, coronary angiography, and coronary artery bypass grafting by age, sex and clinical indicators, Heart, 85 , pp. 680-686.

Brooker, C., Davies, S., Ellis, L. et al (1997) Promoting Autonomy and Independence among Older People: An Evaluation of Educational Programmes in Nursing, English National Board for Nursing, Midwifery and Health Visiting, London.

Bytheway, B. (1995) Ageism, Open University Press, Buckingham.

Bundesarbeitsgemeinschaft der Senioren-Organisationen (Bonn), Europäisches Zentrum für Wohlfahrtspolitik und Sozialforschung (Wien), de senectute (Paris), Institut für Soziale Infrastruktur (Frankfurt) (2001) Chancengleichheit für ältere Frauen in Politik und Gesellschaft. Dokumentation einer europäischen Konferenz am 1./2. Februar 2001 in Brüssel. Stuttgart, Marburg, Erfurt: Verlag Peter Wiehl.

Carpenter, I., Challiner, Y., Coxon, K. et al (2002) An Evaluation of Intermediate Care Services for Older People, CHSS, University of Kent, Canterbury. 
Colmorten, E., Clausen, T., and Bengtsson, S. (2003) Providing integrated health and social care for older persons in Denmark: PROCARE Report, The Danish National Institute of Social Research, Denmark.

Corby, B. (1993) Child Abuse: Towards a Knowledge Base, Open University Press, Buckingham.

Congreskrant OL2000 (2002) Denken en werken vanuit de burger. Den Haag: OL2000.

Cryer, C. and Patel, S. (2001) Falls, Fragility and Fratures (Paper) Proctor and Gamble Pharmaceuticals, UK.

Department of Health (2001a) Older People: National Service Framework for Older People, Department of Health, London.

Department of Health (2001b) Medicines and Older People: Implementing medicines-related aspects of the NSF for Older People Department of Health, London.

Department of Health (2002a) Hospital Episode Statistics December 2002 http://www.doh.gov.uk/hes/tables/tb00701a.pdf.

Department of Health (2002b) The Single Assessment Process - Guidance for Local Implementation Department of Health, London.

Department of Health (2003) Discharge from hospital: pathway, process and practice Department of Health, London.

Donabedian, A., (1980) The Definition of Quality and Approaches to its Assessment Michigan, Health Administration Press.

Dudley, N. J., Bowling, A. Bond, M. et al (2002) Age- and sex-related bias in the management of heart disease in a district general hospital, Age and Ageing, 31, pp. 3-4.

Durkheim, E. (1933) The Division of Labour in Society Free Press.

European Commission (2002-2004) MERI: Mapping existing research and identifying knowledge gaps concerning the situation of older women in Europe Institut fur Soziale Infrastruktur, Frankfurt.

Ex, C., Gorter, K. \& Janssen, U. (2003) Providing integrated health and social care for older persons in the Netherlands: PROCARE Report, The Verwey-Jonker Institute for Research into Social Issues, Utrecht, Netherlands.

Freeman, R. (2000) The Politics of Health in Europe Manchester, Manchester University Press.

Freidson, E. (1970) The Profession of Medicine Dodd, Mead and Co, New York.

Frossard, M., Genin, N., Guisset, M., Villez, A. (2002) Providing integrated health and social care for older persons in France - An old idea with a great future: PROCARE Report, UNIOPSS, France. 
Grilz-Wolf, M., Strumpel, C., Leichsenring, K. and Komp, K (2003) Providing Integrated Health and Social Care in Austria: PROCARE Report European Centre for Social Welfare Policy and Research: Vienna.

Grimley Evans, J. (2001) Ageing and medicine, in: Davey, B., Grey, A., and Seale, C. (Eds.) Health and Disease: A Reader $3^{\text {rd }}$ Edition Open University Press, Buckingham.

Heyman, B. (1998) (Ed) Risk, Health and Health Care: A qualitative approach Arnold, London Hiscock, J. and Pearson, M. (1999) Looking Inwards, Looking Outwards: Dismantling the 'Berlin Wall' between Health and Social Services? Social Policy and Administration, 33, pp.150-163.

Inclusion News (2003) 'Hot Seat: Joe Montgomery' http://www.socialexclusionunit.gov.uk/inclusion news/issue 1/articles?hs j_montgomer y.doc (accessed $4^{\text {th }}$ March 2003).

InterRAI (2001) Interrai Home page - Minimum Data Set (MDS) links: http://nt8380.hrca.harvard.edu/Default.htm

Jefferson, T. and Holloway, W. (1997) The risk society in an age of anxiety: situating fear of crime, British Journal of Sociology, 48, pp. 255-266.

Johnson, T. (1972) Professions and Power Macmillan, London.

Joseph Rowntree Foundation (2003) 'Older People's views on information, advice and advocacy' (Findings) http://www.jrf.org.uk

Kavanos, P and McKee, M (1998) 'Macroeconomic constraints and health challenges facing European health systems' In Saltman, R. B., Figueras, J. and Sakellarides, C. (Eds) (1998) Critical Challenges for Health Care Reform in Europe Buckingham (UK) Open University Press.

Kemshall, H. (2002) Risk, Social Policy and Welfare Open University Press, Buckingham.

Lyon, C. M. and de Cruz, P. (1993) Child Abuse, $2^{\text {nd }}$ Edition, Family Law, Bristol.

Macintyre, S., Ford, G., and Hunt, K. (1999) 'Do women over-report? Men's and women's responses to structured prompting on a standard question on long standing illness.' In Social Science \& Medicine 48:89-98.

McKinlay, J.B. (1975) Processing People: Cases in Organisational Behaviour Holt, Rinehart and Winston, Surrey (UK).

McKinlay, J.B. (1996) 'Some contributions from the social system to gender inequalities in heart disease' In Journal of Health and Social Behaviour 37:1-26. 
Murphy, E. (2001) Micro-level qualitative research, in: Fulop, N., Allen, P., Clarke, A. and Black, N. (Eds.) Studying the organisation and delivery of health services: Research methods Routledge, London.

OECD (2003) OECD Health Data http://www.oecd.org (Frequently Asked Data).

Ong, B. N. (1993) The Practice of Health Services Research, Chapman and Hall, London.

Roth, G and Reichert, M (2002) Providing Integrated Health and Social Care for Older Persons in Germany PROCARE Report, Institut fur Gerontologie, Dortmund, Germany.

Salonen, P. and Haverinen, R. (2003) Providing Integrated Health and Social Care for Older People in Finland: PROCARE Report, National Research and Development Centre for Welfare and Health, Helsinki, Finland.

Schieman, S and Campbell, J E (2001) 'Age Variations in Personal Agency and Self-Esteem: The Context of Physical Disability' In Journal of Aging and Health Vol 13 no 2 pp 155185.

Stanley, N., Manthorpe, J. and Penhale, B. (Eds) (1999) Institutional Abuse: Perspectives across the life course London: Routledge.

Strang, J and Stimson, G.V. (Eds) (1990) AIDS and drug misuse: The challenge for policy and practice in the1990's Routledge, London.

Taleporos, G and McCabe, M. P. (2002) 'The impact of self-esteem, body esteem, and sexual satisfaction on psychological well-being in people with physical disability' In Sexuality and Disability v.20 no 3 pp177-183

Taylor-Gooby, P. (2000) Risk and Welfare, in: Taylor-Gooby, P. (Ed.) Risk, Trust and Welfare, Basingstoke, Macmillan, pp. 1-18.

Tinker, A. (1996) Older People in Modern Society, $4^{\text {th }}$ Ed., Addison Wesley Longman, London.

Tudor Hart, J (1971) 'The Inverse Care Law' Lancet pp.405-412.

Twigg, J. and Atkin, K (1994) Carers Perceived: Policy and practice in informal care, Open University Press, Buckingham.

Wagner, L. (1994) Innovation in primary health care for elderly people in Denmark. The Nordic School of Public Health, Gothenburg.

Wagner, L. (2000) 'Ti år efter - aktionsforskning anvendt i udvikling af ældres pleje og omsorg (Ten years after - action research used in development of health and care for elderly)', in: Gress, N. \& Graugaard, K. (eds.) Klinisk Sygepleje 1, 2 og 3 - Praksis \& Udvikling (Clinical nursing 1, 2 and 3-Practice \& Development). Viborg: Akademisk Forlag.

Wildavsky, A. (1979) The Art and Craft of Policy Analysis, Macmillan, Basingstoke.

Wilkinson, I. (2001) Anxiety in a Risk Society Routledge, London. 